Ayşe Tuba Karagülle Kendi

Funda Uysal Tan

Mustafa Kendi

Sevda Yilmaz

Sinef Huvaj

Serdar Tellioğlu

\section{MR spectroscopy of cervical spinal cord in patients with multiple sclerosis}

Published online: 13 August 2004

(c) Springer-Verlag 2004

The online version of the original article can be found at http://dx.doi.org/10.1007/ s00234-004-1231-1

Present address: A. T. K. Kendi

Center for MR Research,

University of Minnesota,

2021 6th Street SE, Minneapolis,

MN 55455, USA

F. U. Tan $\cdot$ S. Tellioğlu

Neurology Department,

Kırıkkale University School of Medicine,

Kırıkkale, Turkey

M. Kendi

211121 th Street S21,

Minneapolis, MN 55404, USA

S. Yilmaz $\cdot$ S. Huvaj

Radiology Department,

Kirıkale University School of Medicine,

Kırıkkale, Turkey

A. T. K. Kendi $(\bowtie)$

Radiology Department,

Kırıkkale University School of Medicine,

Kırıkkale, Turkey

E-mail: drtubakendi@yahoo.com

Tel.: + 1-612-6262001

Fax: + 1-612-6262004

\section{Neuroradiology}

s00234-004-1270-7

Due to an unfortunate error, the name of the fourth author, Sevda Yilmaz, was deleted from the HTML version when the proof corrections were carried out. 